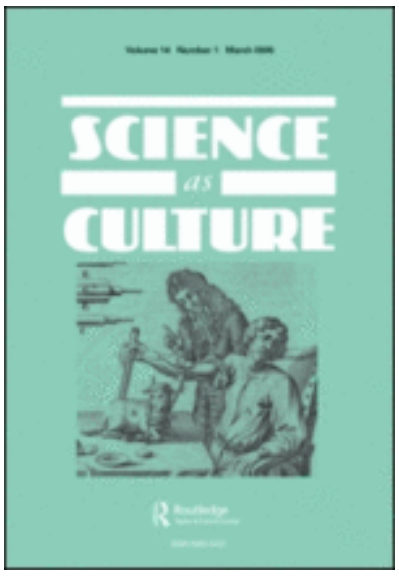

\title{
Techno-securitisation of Everyday Life and Cultures of
} Surveillance-Apatheia

\begin{tabular}{|c|c|}
\hline Journal: & Science as Culture \\
\hline Manuscript ID & Draft \\
\hline Manuscript Type: & Special Issue \\
\hline $\begin{array}{r}\text { Date Submitted by the } \\
\text { Author: }\end{array}$ & $n / a$ \\
\hline Complete List of Authors: & Ellis, Darren; University of East London, \\
\hline Keywords: & Surveillance-Apatheia, Surveillance, Techno-security, Affect \\
\hline
\end{tabular}

\section{SCHOLARONE"} Manuscripts 


\title{
Techno-securitisation of Everyday Life and Cultures of Surveillance-Apatheia
}

\begin{abstract}
As a result of digital technologies and the internet becoming increasingly ubiquitous, security technologies and surveillance systems are becoming ever more embedded into everyday life, encroaching upon peoples' privacy. Yet concerns about this appear to be relatively mute. Why is this the case? Is the public generally indifferent about it or perhaps silently in agreement with its increased presence? There are two overarching attitudes that are popularly cited, portraying a need either for security or privacy. However, beyond these initial attitudes, when participants in this study were interviewed, more complex, ambivalent and contradictory positions began to emerge. As techno-security systems are becoming increasingly complex, multiple, normative, hardly recognisable, often covert and all encompassing, positioning oneself in relation to them can be a difficult process. Hence the techno-securitisation of everyday life has psychological effects which are multiple and largely unconscious. Indeed, we are all somewhat uncertain about the spin-offs of surveillance technologies and practices - in terms of their capabilities, who has access to the data they produce, and the ways that they might affect subjectivity. Rather than being plainly indifferent or silently consenting to increased techno-securitisation, some participants in this study developed an attitude of surveillance-apatheia. They tended to state that 'as there is no avoiding these systems and not much one can do about them, why consciously worry about them?' This attitude is not necessarily a lack of interest, but rather a way of managing associated undesirable affects, feelings and emotions.
\end{abstract}

Key words: Surveillance-Apatheia, Surveillance, Techno-security, Affect

Illustration 1

\section{Introduction}

Recently in Europe there has been concern, perhaps anxiety, or even paranoia reported in the media about employers' rights to monitor private internet use at work. This anxiety comes partly from the European Court of Human Rights' decision in the Bărbulescu v Romania case that personal use of the internet at the workplace is not necessarily protected under Article 8 (the right to respect for private family life) of the European Convention on Human Rights (European Court of Human Rights, 2016). This ruling created a flurry of headlines, at least in the UK. For example, in response to this ruling The Sun newspaper ran a story entitled, "Here are all the ways your boss can spy on you at work: It's not only your emails they can see..." (The Sun, 2016). They ran a frontpage headline stating "BOSS CAN SNOOP ON YOUR PRIVATE EMAILS". The Daily Mail stated, "Bosses can now read staff's private messages sent on WhatsApp and similar forums during work hours, European court rules" (The Daily Mail, 2016) with the front-page headline "BOSSES FREE TO SPY ON EMAILS". The Metro (2016) ran the front-page headline "Your boss now has the right to snoop on all your on-line private messages".

Yet later the Council of Europe accused the British press of inciting a "misinformed media storm", given that the court's decision on domestic judges differs from country to country. For example, the UK are under no obligation to follow decisions, but its Human Rights Act requires judges to "take them into account" (Cutting, 2016). The Council further stated that "Legislation has not been altered as a result of Tuesday's judgment, either in Romania or any of the 46 other Council of Europe member states, which include the UK." On a positive note, it hoped this would "help persuade workers and their bosses to clarify exactly where the boundaries lie concerning personal communications at work." But The Guardian (2016) newspaper posed the question, "Why is it that people 
understand this easily when thinking of their workplace, yet find it so difficult to extend the same healthy suspicion to their governments?" Indeed, The Guardian (2016) claims that this event got more traction in the news than Edward Snowden's revelations, which Fleet Street mostly greeted with apathy.

A general silence or indifference towards government surveillance apparently extends to corporate forms of surveillance, which is sometimes referred to as state-corporate surveillance. Scholars elsewhere have similarly found this generalised silence and/or indifference, for example, a recent ESRC funded project entitled Digital Citizenship and Surveillance Society suggest that the Snowden leaks

provided unprecedented insights into the workings of state-corporate surveillance programs based on the interception of Internet traffic and "bulk" collection and analysis of metadata by security agencies in Western democracies, most notably the U.S. National Security Agency (NSA) and the British Government Communications Headquarters (GCHQ) (Dencik and Cable, 2017, 763)

Surprisingly, public opinion has remained "considerably muted, and there has been little evidence of public outcry" (Ibid). Denick and Cable (2017) state that this appears to be a much wider cultural pattern across countries. For example, HBO's John Oliver jovially mocked American citizens for their lack of concern about Snowden's revelation on 'Last Week Tonight' (2015). Although the interviews that they conducted in Times Square New York were far from scientific, they nonetheless portrayed a distinct lack of concern; for example, most interviewees did not even know who Edward Snowden was.

Our research project, "Everyday Experiences of Surveillance", investigated the multiple forms of surveillance practices and their everyday effects in the South East of England. This project also found a significant amount of what may be identified as indifference and/or apathy, particularly towards state-corporate forms of surveillance practices (Ellis, Harper, and Tucker, 2013; Ellis, Tucker and Harper, 2013). This paper therefore attempts to address the questions: What underlies this apparent indifference and/or apathy towards state-corporate forms of surveillance? Does this muted response equate with consent, indifference, apathy, or something else?

To address these questions, this paper firstly discusses the concepts of techno-security and the technosecuritisation of everyday life. These concepts particularly draw attention to how surveillance technologies have become pervasive, normalised and imbue day-to-day activities. Secondly, it conceptualises affect in order to theorise how the techno-securitisation of everyday life is often non-consciously managed through the formation of surveillance-apatheia, by contrast with apathy, indifference and/or compliance. Thirdly, the paper draws on some empirical semi-structured interview data to further analyse the techno-securitisation of everyday life in relation to affect and surveillance-apatheia.

\section{Techno-securitisation of everyday life}

It is over a decade ago that scholars argued that we are now 'living in a surveillance society' (Wood, Ball, Lyon, Norris, \& Raab 2006). To think in terms of a surveillance society, Wood et al., suggest, is to:

throw into sharp relief not only the daily encounters, but the massive surveillance systems that now underpin modern existence. It is not just that CCTV may capture our image several hundred times a day, that check-out clerks want to see our loyalty cards in the supermarket or that we need a coded access card to get into the office in the morning. It is that these systems represent a basic, complex infrastructure which assumes that gathering and processing personal data is vital to contemporary living (Wood, Ball, Lyon, Norris, \& Raab, 2006, 1)

Since the publication of this report, CCTV use in the UK has interestingly fallen in relation to local authority use. In 2016 a Big Brother Watch report revealed through a number of freedom of information requests, that there has been a $12.5 \%$ decrease from 2012 in the amount of CCTV cameras that local authorities' control. In fact, there have been significant decreases in the amount spent on CCTV cameras which includes costs of: installation 
(57.3\%), maintenance (42\%), and the salaries of operators (47\%). Although Big Brother Watch state that these figures are welcome in relation to privacy concerns, they warn that "We are on the cusp of yet another breakthrough in technology, the rise of smarter technology, smarter cities, facial biometrics, 3D scanning and other more accurate forms of surveillance technologies are all a blink away" (Big Brother Watch, 2016, 5). So, while conventional CCTV camera use by local authorities is waning in some areas of the UK, they are increasingly adopting new digitized and more sophisticated forms of surveillance practices.

As much of this special issue will draw attention to, new surveillance technologies and practices developed for military objectives, ends up in the private sector (and visa-versa) (see also, Hayes, 2012 and Wilson, 2012). Hence military predecessors have deeply impregnated the surveillance society, according to Weber (2011); examples include: the internet, RFID (radio-frequency identification) and satellite technologies such as GPS (global positioning systems). In the context of border control, Marin (2017) describes what she calls, a technosecuritisation of borders. In this context, she discusses how techno-securitisation can be framed through witnessing, in the past few years, "a consolidation of securitization discourses and practices, namely with a stabilization of the trend of deployment of all the available technological tools in border surveillance" (107).

Similarly, there is also a techno-securitisation of everyday life occurring through the transference of surveillance technologies, discourses and practices, for example, particularly evident in: the labour market, medical institutions, police work, legal institutes, communications, border controls, and even entertainment (Wilson, 2012). Although this has a long history with some poignant moments, for example the end of the cold war, it has been radically prolific since the so called 'war on terror' wherein targets are no longer located within geographic locations, but scattered throughout communities. Obtaining information has moved centre stage and new forms espionage through the use and infiltration of digital communication technologies have become key. The transference of military ideas of tracking, identification and targeting civilians represents, Graham (2013) argues, "attempts to translate longstanding military dreams of high-tech omniscience and rationality into the governance of urban civil society" (11).

Sophisticated devices each incorporating a diverse range of applications, increasingly saturate society and everyday life. The potential for what Winner way back in 1977 called 'function-creep' in relation to technosecurity is astounding and the complexities of which are somewhat incomprehensible. Ofcom (2015) found that $93 \%$ of UK adults reported owning a mobile phone in 2015. There is almost three times as many people in the UK (91.6\% of the population) using the internet in 2013 as there was in 2000 (Internet World Stats, 2013). And of course, social networking site use has exponentially increased with Facebook alone widely reported to have reached over a billion daily users in 2015.

Whilst there has been a media outcry in the UK related to the relatively spurious claims that employers have enhanced rights to conduct forms of surveillance on employees in the work-place, the UK government in 2016 obtained royal assent for the Bill of Investigatory Powers, now entitled the Investigatory Powers Act 2016. It entitles equipment interference, or what is also known as computer network exploitation (CNE) (dubbed a hacking power), which allows the security services to access computers and mobile devices and download their data (see also the Home Office's Equipment Interference Code of Practice, 2016).

A form of corporate surveillance, that participants in the present study particularly discussed, is that which occurs through the commercial sector. For example, digital and online marketing practices seek to understand the consumer through a variety of their data footprints. Since the advent of Web 2.0, this form of surveillance has become increasingly participatory as individuals divulge personal information and interact in various ways with corporations online. The individual in this context is both consumer and producer, often referred to as 'prosumer' (Beer and Burrows, 2010). For example, the prosumer supplies opinions, preferences, and a multitude of other online habits, which numerous agents use, for example, for targeted marketing. This sort of 'collaborative surveillance', Pridmore suggests, (2013) leads the individual to subtly consenting to divulging URL: http:/mc.manuscriptcentral.com/csac 
personal information and interacting with corporations.

Additionally, we have recently found that Cambridge Analytica has exploited social media by dishonestly purchasing and tapping into consumer datasets from Facebook to undertake psychographic profiling and microtargeting of voters from marginal constituencies (Sampson, Ellis and Maddison, 2018, 2). Indeed, the parent company of Cambridge Analytica is the Strategic Communications Laboratories (SLC Group), linked with such practices as military disinformation campaigns on social media (Vogel, 2015). Indeed, on its website (slcgroup.cc/home) it stated that it provides analytics and strategy to governments and military organisations world-wide. Thus, the military objectives of high-tech omniscience penetrate deep into civil society.

YouGov (2006) conducted a poll in the UK asking people about different aspects of surveillance. The results of which were quite ambivalent and perhaps confusing. For example, respondents agreed with the description that Britain is a surveillance society, but in addition to this there was quite a lot of support for a variety of forms of surveillance. Similarly, qualitative research conducted by myself and two colleagues (Ellis, Tucker and Harper, 2014), found that individuals often have contradictory and ambivalent attitudes towards surveillance systems and practices.

There tends to be two dominant public discourses that have given rise to attitudes towards surveillance, giving precedence to either concern for security or privacy. A typical refrain heard from individuals positioning themselves as pro surveillance is 'if you have nothing to hide, then you have nothing to fear'. At the other end of the spectrum a typical refrain is 'we are living in an Orwellian Big Brother state' (Solove, 2007). We had found that the discursive positions and attitudes of individuals quite often fluctuate and shift in relation to these opposing discourses (Ellis, Tucker \& Harper, 2014). It became apparent that many of the participants had not given much previous consideration to such matter and so attitudes in the interview context were still relatively raw and flexible. We might ask why people have not given it much thought when surveillance technologies and practices are so ubiquitous?

A variety of agencies has ingrained techno-security so widely into everyday cultural practices that it has become a normal and unnoticed part of many people's everyday life. Webster and Murakami Wood suggest that the normalisation of surveillance occurs when it has colonised the emotional, symbolic, and cultural domains of a society, "it is about how these are embedded in the norms and institutions of society and how they are reflective of other aspects of modern society" $(2009,265)$. The complexity of the systems is likely to diminish the ability to meaningfully comprehend them in day to day activities and ironically their ubiquity increases their normalisation, as although they are everywhere, they are often hidden in plain sight (and of course they can be more explicitly covert).

Similarly, Dencik and Cable (2017) argue that contemporary surveillance practices incorporate "a lack of transparency, knowledge and control over what happens" it inculcates "feelings of widespread resignation" leading to a condition they identify as "surveillance realism" (763). Surveillance realism is a concept Fisher (2009) developed from Fisher's (2009) notion of 'capitalist realism', and refers to attitudes towards surveillance practices as being coloured by a lack of imagined alternative possibilities because of their hegemony and normalisation. This does not mean that the public welcomes them, indeed they suggest that there is widespread recognition of their fallacies and injustices. Thus, surveillance realism leads to a muted response from the public and a general sense of disempowerment, they state "we see a kind of resignation to the overpowering nature of contemporary surveillance deeply embedded in everyday life. .." (773).

In addition to the feelings of impotency (disempowerment and resignation), those who desire to increase and in addition normalise the techno-securitisation of everyday life, can do so through what Furedi (2006) denotes as a politics of fear. For example, through inciting the: fear of terrorism, fear of crime, fear of ill health, fear of war and generally fear of the other. The public then tolerate ubiquitous techno-security to combat these fears, which URL: http:/mc.manuscriptcentral.com/csac 
in turn competes with and often supersede the effects of being surveilled. Arms manufacturers who sell mainstream surveillance products and security systems, the hawkish politicians and various facets of the mainstream media (fear sells news), produce discourses related to these fears. Thus, fear abates insecure feelings and emotions of the techno-security in everyday life. As described later in this paper, surveillanceapatheia facilitates the management of these fears and anxieties alongside other affective activities.

\section{Third realm of affect}

This then begs the question: in what ways does every-day techno-security and surveillance effect citizens? To begin to address this question, it is helpful to draw on conceptualisations of affect. The conceptualisations of affect drawn upon facilitate insights which go beyond understandings of techno-security and surveillance producing particularised forms of emotions or attitudes which are conscious, such as fear, vulnerability, security and trust. The affect theory devised here draws upon a line of thought stretching from Spinoza through to Deleuze and Guattari (1987) and Massumi (2002) (see Ellis \& Tucker, 2015; Gregg \& Seigworth, 2010; Wetherell, 2012). Affective phenomena, Cromby (2011) suggests, "consists of textures, intensities, directions, desires and valences that are known corporally before they are identified linguistically" (83). Deleuze and Guattari draw on a conceptual distinction between two realms of existence: the virtual and the actual. The virtual is a dynamic realm providing the conditions of potentiality. It is a realm incorporating pre-conscious phenomena that is yet to be linguistically fixed and located. This is distinct from phenomena that has been determined (actualised) through socio-cultural linguistic grids of meaning, for example particularised feelings and emotions that have become conscious and named. The realm of the virtual therefore is particularly difficult to empirically investigate as by its very nature it is intangible.

Ellis, Tucker, \& Harper (2014) argued that the affective activity which flows between and through bodies in relation to ubiquitous surveillance, can create, what Anderson (2009) describes as affective atmospheres. The term atmosphere here has worked well in relation to the effects of surveillance as it involves bodily feelings. For example, the atmosphere that one senses when entering a room of people or the atmosphere of an airport which saturated with security systems. These are likely to affect individuals but not necessarily in a conscious way. This atmospheric sense is tantamount to what McCormack identifies as a third realm of affective activity (2008). This third realm is galvanised between the actual and virtual realm where there is the registration of intensities, such as, fluctuated heart rate and the respiratory system (Massumi, 2002). Moreover, this third realm of affect can discursively manifest itself in speech acts that we often overlook as being irrelevant because they appear relatively incomprehensible, lacking coherence and other linguistic structural features, but entail distinct somatic and affective tones (Ellis, Tucker, \& Harper, 2013). Thus, this third realm, which incorporates the affective atmosphere, is to some extent empirically verifiable in the research context.

Surveillance practices and discourses can produce a complex mix of affects that people find difficult to engage with and appropriately linguistically and culturally qualify (Ellis, Tucker \& Harper, 2013). In this paper, the Stoic concept and practice of apatheia forms a theoretical framework for further theorising some of the psychocultural responses related to the effects of living in a called surveillance society. Apatheia for the Stoics denoted a much more positive disposition to what is now call apathy. It was about reducing the affective capacity of phenomena that are uncontrollable. The Stoics saw the achievement of apatheia through moderating responses to the external world, rather than trying to change aspects of it, particularly if there is not much one can do about them. In most circumstances, the primary affective dimension of any stimuli is unavoidable, the initial affective impression is what was known by the Stoics as the first movement of the soul (in Ancient Greek propatheia; in Latin primus motus). Although scholars dispute the precise origins of the term propatheia, there is consensus that it was a concept developed by the Stoics (Layton, 2000). For example, Seneca states that propatheia entails "the involuntary motions of the soul that are not emotions (affectus) but the beginnings that are preliminary to emotions" (Knuuttilia, 2004, 64). 
The Stoics believed that one could obtain eudaimonia (the good or virtuous life) if one learns to develop the correct cognitive judgments. One key way of doing this is learning not to reduce the propatheia's psychological effect on everyday life. The Stoics saw this as possible as the second movement, which is the cognitive judgment of the propatheia is voluntary, which means that one can manipulate it. The Stoics advocated therapeutic activities to decrease the power of the first movement's effects by regulating the second movement. For example, Posidonian prescribed specific diets and music to increase control, but overall the key concern was to moderate one's beliefs through the formation of the right habits (eupatheia). This form of therapeutic practice came to be known as psychagogy and has certainly influenced many fields of what we call psychotherapy today, particularly cognitive behavioural therapy (see Sorabji, 2004).

The concept of apatheia works particularly well in the context of the affect theory drawn upon in this paper, as the involuntary motions exist within a third realm. The third realm exists between the actual and the virtual. For example, the body may be non-consciously moved by affect in some way, but the affectivity has yet to reach conscious deliberation. Registration is therefore not semantic but somatic. It is not until invocation of the second movement occurs, the cognitive judgment of the primary movement, that the underlying affective activity becomes what may be determined as an emotion proper, a particularised form of emotion. Thus, the concept of apatheia and affect theory, both draw attention to that which exists outside of the discursive realm.

Affect theory, like the concept of apatheia, is rooted in ancient and medieval philosophies. Contemporary affect theories have been theorised in different ways, utilising a variety of historical concepts (for example, see Gregg and Sedgworth's (2010) Affect Theory Reader). The concept of apatheia emerges here in like manner, but with some further qualification. One might ask why not use psychological concepts such as suppression or repression to denote this activity? Although forms of suppression and repression may be involved, the practice of apatheia is a more nuanced process which is particularly concerned with not allowing things that are out of one's control to agitate the soul. Apatheia for the Stoics was about learning to live in a way where one is free from the passions. The concept of apatheia therefore used in this context denotes a particularised form: surveillanceapatheia. Surveillance-apatheia then is an attitude that individuals learn, which decreases the agitation and anxiety produced by surveillance systems and their associated practices. This attitude stems from the perception that there is little one can do to avoid them, so why concern oneself with deliberation and anxiety of them.

The data drawn upon in this paper derived from semi-structured interviews with thirty-one adult participants residing in London and the surrounding areas. The project received ethical approval from a university research ethics committee. Nineteen of the participants were female and twelve were male with an average age of 41.2 . The interviews took place in either a public place that was convenient to the participants or on campus at a London university. The interview protocol focused upon citizens' knowledge of the different forms of surveillance systems, their everyday experiences of them, the role they believed surveillance systems play in contemporary society, and their views on balancing desires for security with desires for privacy.

Quite often, reports of opinions regarding issues related to security and privacy are relatively simple and fixed. This is because the methodologies used to generate insights are often of a quantitative nature; for example, opinion polls and Likert questionnaires. Although these can produce some insight into generalised and aggregated opinions they do not sufficiently capture the nuanced ways that people position themselves in relation to techno-security phenomena and experience them, and more importantly the effects that these are having upon subjectivity and cultural practices. Narratives (derived from interviews) are useful in drawing out the multiple ways that people understand, experience and position themselves in relation to the technosecuritisation of everyday life; they enable researchers to empirically further comprehend the complexity of its effects.

Illustration 2 
Many of the participants throughout the interviews began their discussion by positioning themselves through utilising either security or privacy discourses. These positions often fluctuated, becoming more fluid, contradictory, context dependent, and ambivalent as the interview unfolded and the scope of the subject became more apparent. Therefore, many of these opinions and understandings of surveillance would have escaped a poll or questionnaire. For example, in the following abstract Mohammed discusses how he dynamically decides between distrust and trusting positions.

Mohammed: <I: Do you do any online shopping? In terms of bank details bank accounts $>$ yes I do <1: Do you trust online shopping? > Erm I can trust online, I don't but I can (.) if I see some features on that website that I'm aware of that ok this proves there is safety like there is a padlock, there is lock and there is SSL and all these technologies implemented on that website then I'll feel safe using my financial card or whatever in that sense (.) but if there is if I suspect the website to be dodgy like the link that your personal details would be going to when you click and submit or check out or whatever if I don't trust that link then I wouldn't shop

It would be incorrect to simply surmise that Mohammed distrusts or indeed trusts in the security technologies related to internet shopping (for further discussion of the dynamics of trust in this context: Ellis, Harper, \& Tucker, 2013). His trust is contextually specific and attuned through prior experience and knowledge.

Mohammed produces a nice example of how one may dynamically form relationships with digitised security systems. In the below example he portrays how trust is something that requires effort to acquire rather than something that passively emerges. For example, the phrase "I can trust online, I don't but I can". Hence, we find some complexity and ambiguity related to his positioning. Mohammed was an Information Technology graduate and so has much experience and knowledge of networked systems. In the following extract, we find Margaret depicting herself as someone who is presently less able to develop a trusting position towards an online security system.

Margaret: <1: Right, do you do any shopping online?> Occasionally <l: right> l've bought erm a pram for my daughter but that's about it and a couple of silly things I don't really do it I don't use my computer to shop I don't trust it I just don't trust it I wouldn't wanna put my bank details in the computer <I: ok> I just don't I don't know why maybe it's 'cause I'm I don't go on computers a lot anyway (.) probably my age really that you know its a technology I'd rather just l'd do it on the phone to companies that I use that I know that I trust

Her narrative portrays distrust as being a result of a lack of experience of using these technologies. However, she is open to the possibility that at some point in the future she may be able to become more confident and trusting of the internet. Again, the opinion polling methods would not have been able to reflect this relatively complex attitude as she is not simply portraying a distrusting position that is static, but she goes on to think about her future relationship with this form of technology.

Margaret: I mean I think once I get to start to use it a lot more and I get more confident then I probably will because I know my computer's got a security thing on it and obviously you know passwords and things

So, Margaret portrays some preliminary insight into internet security related phenomena, by showing that trust may be obtainable in the future. Overall however, the above extracts convey a sense of some of the complexity related to the everyday deliberation that may occur as a result of the various techno-security systems.

\section{Ambivalence}

Indeed, it was quite clear through the data set that attitudes and accompanying thoughts and feelings were not simply dichotomised, but contextual and existing in what is like a multiverse of opinions which may not appear 
logically coherent. The following extract is another example of ambivalent positioning wherein Michelle discusses the kind of tracking that she considers occurs through her loyalty card use.

Michelle: , well yeah when I'm ... supermarket shopping <ok> they use a loyalty card <yeah> and I know that all of that data, I know that Sainsbury's know what I buy every time I go $<\mathrm{mm}>$ and I'm targeted every month with a magazine or every quarter with a magazine because I've got children and because I buy nappies and <Interviewer: mmm > formula and stuff I get a certain type of magazine and I know older people who buy different things get a different magazine <right, ok> so that's you know that's spot on analysis really <Interviewer: $\mathrm{mmm}>$ whoever's doing their marketing < Interviewer: yeah> is they've got it down to a tee really < Interviewer: $\mathrm{mmm}>\ldots$ so, in that respect that's a good thing but it's also a bit disconcerting that somebody out there knows what's in my shopping trolley every time [laughs] I go shopping

What is of additional interest from the above extract is the simultaneity of contrasting sentiments that Michelle portrays. On the one hand, she finds the level of surveillance that she appears to be undergoing in relation to the loyalty card as being helpful: the targeted marketing can be useful it would appear. On the other hand, there is some disconcertment as she perceives the technological processes as involving 'somebody out there' knowing what is in her shopping trolley. The cultural discourses of fear that Furedi (2006) discusses, perhaps feed into this process. Although the technology behind the targeting is rather impersonal, for example, digitally produced through algorithms, it seems to feel personal for Michelle and so to some degree human. Here then the simultaneity of seemingly opposing sentiments (secure and insecure) are perhaps difficult to psychologically understand and manage, creating a sense of incongruence and cognitive dissonance. There may be then a kind of psychological splitting occur, wherein one adopts either of the ostensibly opposing discursive attitudes towards techno-security (for example, somewhere between paranoid and trusting positions). Indeed, one of the striking features of contemporary techno-security is its inherent contradictory characteristics:

"entailing elements that are both: ever-present and yet absent (unnoticed), material (embodied through the CCTV camera) and yet ethereal (the watcher of the camera is invisible), geographical (located in a particular time and space) yet trans-geographical (transmitted to other times and spaces through the internet), and facilitating a safe and secure environment and yet facilitating distrust (invading privacy)" (Ellis, Tucker, \& Harper, 2014).

It is perhaps therefore not surprising that its effects upon individuals can be equally complex and contradictory. For example, although in the below extract Samantha is discussing the rather surreptitious and complex technosecurity systems of the 'external' world, it can also be read as a metaphor, or perhaps a parallel process, of 'internal' psychological processes.

Samantha: " so I know there are things going on in the background but how all of this information gets to be processed that I don't know but I'm sure that my my rights are being exploited somewhere on the way"

The "background" here represents the techno-securitisation of everyday life. Thoughts and feelings about these pervasive surveillance systems can be difficult to manage. The multiple processing of surveillance data that occurs in the background of the external world is relatively non-consciously perceived and affectively internalised. As the techno-security systems themselves grow in complexity, so must our understanding of them. Hence, we find Samantha having a relatively vague sense that something is awry in relation to her rights and the techno-securitisation of her everyday life.

Lyon (2015) argues that the Snowden revelations revealed our deepest fears of the depth and amount of surveillance certain governments undertake. Many who had been relatively paranoid about surveillance practices by the government have principally had their suspicions confirmed. These interviews occurred before the Snowden revelations and stories that may have appeared rather wild and overly paranoid do not seem to so 
farfetched now. For example, in the following extract we find Brehan's narrative denoting a relatively suspicious position.

Brehan: "but even when it comes to phones people say that even if you switch off your phone, you think it's off <Interviewer: mmm> it's not, they can still, someone can still be listening in to you < Interviewer: really?> yeah you've got to disconnect the battery < Interviewer: really?> yeah yeah so even if you've just got your phone and < Interviewer: and it's off?> and you switch it off, and you put it there you can still pick up you've got to disengage the battery, take it off"

Here we find Brehan quite concerned that the microphone in his mobile phone can be listened to. Although this level of surveillance may be quite farfetched, the Snowden revelations reported that the US NSA and the UK GCHQ hacked into the biggest manufacturer of Sim card made by the Dutch firm Gemalto. Thus, paranoid narratives that had been culturally circulating about such practices, were not actually too far from the truth it seems, and are no doubt continuing to affect attitudes and behaviours, particularly for groups of people who are likely to feel targeted because of their social identity (race and religion for example). These types of practices are now likely to increase, at least in the UK with the introduction of the Investigatory Powers Act 2016, wherein the security services can obtain the power to lawfully infiltrate communications systems.

\section{Surveillance-apatheia}

Many other participants shared Samantha's concern that there are "things going on in the background" that are likely to be exploiting their rights in some-way. It is a concern that becomes actualised in such activities as disengaging the battery of a mobile phone when having a private conversation, avoiding internet shopping, being wary of what one puts into a shopping trolley and learning about internet security. These were some of the ways that participants portrayed themselves questioning and resisting state and corporation surveillance practices. Yet of importance for the context of this paper is that one of the things that was relatively surprising, was that some participants portrayed expressed wilful attempts to not think about such things. That is, participants reported experiences and affects related to the techno-securitisation of everyday life as being actively suppressed. In the below extract, Arthur describes a subconscious awareness of the multiple surveillance systems, conditioning himself to deal with it, but in ways that are not so conscious.

Arthur: "the fact that I've probably conditioned myself to you know that subconsciously I'm aware of it so I might not think I'm aware of it every day but somewhere in my subconscious I am sort of dealing with it (2) I don't know how it affects my behaviour"

As discussed, an attitude of apathy (being indifferent) usually denotes a person having no interest or concern about something, it has a negative connotation. This seemed to be the case for many of the participants' interviewed. They sometimes presented as though they were indifferent, unconcerned and moreover unaffected. Denise seems to imply this.

Denise: "[and about your data and things in online shopping] Sorry? [Does it affect your life?] I try not to think about it"

Yet trying not to think about it perhaps points to something else. It suggests that effects of surveillance are affective in some way, but not to the extent that individuals allow it to surface into consciousness. Allowing them to surface results in individuals having to actively deal with emotions and feelings which may be contradictory, paranoid, multiple and therefore difficult to manage. A better strategy therefore maybe to learn to suppress the affect.

Tracy: "you learn to block it even though we can see on the cameras what is going on [mmm] you know"

What is of interest, with respect to experiencing techno-security, is that individuals here seem to be incorporating into their everyday lives, an aspect of psychagogic practice, namely surveillance-apatheia. Some 
participants seem to have adopted this practice, not through external instructions on how to live the good life, but rather through individually and unconsciously adopting suppression strategies. 'Trying not to think about it', 'learning to block it', and 'conditioning oneself', these are all devices which the participants explicitly mention that allow them to moderate concern and hence lower, for example, associated anxiety and fear. Rather than denoting this attitude as reflecting some form of cultural apathy, in which individuals just do not care or not bothered about issues related to privacy and human rights, an attitude of apatheia may reflect a deeper wisdom or perhaps way of coping. As techno-security systems are becoming increasingly complex, multiple, normative, hardly recognisable, often covert, and all encompassing, the data above suggests that the associated affects are difficult to process and hence regulate; therefore, it is perfectly reasonable to hold the position that as there is no avoiding these systems and not much one can do about them, then it is probably better to learn not to be explicitly concerned about them.

However, it may be argued that emotion and affect is an important aspect of our relation to techno-security and there is a danger in giving way to surveillance-apatheia in this context. I recently received a courtesy email from one of my credit card companies advising me on how to be alert to credit card fraud. It listed "five simple rules for beating financial fraud". These consisted of

1) Never tell anyone your security details, like your PIN or banking password

2) Don't assume an email or phone call is genuine

3) Don't be rushed - a genuine organisation won't mind waiting

4) Listen to your instincts - you'll know if something doesn't feel right

5) Stay in control - don't panic and make a decision you'll regret

Although rules $1-3$ were obvious, it was 5 and particularly 4 that caught attention. The above account of surveillance-apatheia may seem to suggest that this state leads one not to listen to some instincts and feelings so that panic (or anxiety) does not ensue. Arguably it is important to ensure our senses are alert to the dangers of techno-security. Crawford and Hutchinson (2015) remind us that,

Emotions also play an important role in shaping how we experience security measures, how we respond to individual and group perceptions of insecurity and traumatic events, and the practices we engage in to manage our own safety (15).

However, what is being drawn attention to in this paper however, is not that people are absolutely indifferent and detached from the rather more explicit dangers related to digital technology, such as explicit experiences of credit card fraud, but rather the techno-securitisation of everyday life.

The focus here is the continued experience of seemingly low levels of monitoring and even manipulation of dayto-day activities. Its effects are subtle and form part of the normalised backdrop of life. The data suggests that there are times when it is too difficult to ignore, but also there are examples of an active form of suppression. The trade-offs are perhaps quite alluring: a belief in enhanced security, continued use of digital communication systems, and what appears ultimately as a low level of anxiety that can remain unconscious. As techno-security powers continue to increase, as outlined for example in the Investigatory Powers Act 2016, it will be interesting to see how much of this is containable through processes of surveillance-apatheia.

\section{Conclusion}

Reported attitudes towards state-corporate surveillance often portray cultures of indifference and therefore compliance (Dencik and Cable, 2017; Ellis, Harper, and Tucker, 2013; Ellis, Tucker and Harper, 2014 Pridmore). This paper investigated whether this apparent muted response to the proliferation of technological surveillance 
practices equates with consent, indifference, or something else. It coined the term surveillance-apatheia, to theorise what underlies some of this general trend.

Additionally, polls and surveys concerned with attitudes towards surveillance tend to find contradictory and ambivalent viewpoints towards surveillance phenomena (for example see YouGov, 2006). Attributing this to the public's indifference or lack of concern does not sufficiently address the complexity of everyday experiences (Dencik and Cable, 2017; Ellis, Tucker and Harper, 2013; Ellis, Harper and Tucker, 2013). Therefore, qualitative interview data on the subject of surveillance was drawn upon in this paper to enable a more detailed analysis of attitudes towards surveillance. The data analysis firstly showed how opinions were often nuanced in ways that would not be meaningfully detected in surveys or polls. Firstly, opinions can be context dependent, fluctuating and processual. Secondly, attention was drawn to people's difficulty of dealing psychologically with the complexities of what was analysed as the techno-securitisation of everyday life. For example, at times seemingly opposed sentiments can be simultaneously experienced, leading to dissonance and incongruence. Thirdly, it was found that some participants wilfully supressed associated thoughts and feelings as they were difficult to consciously deal with. Adopting this strategy can lead to the appearance of an attitude of indifference and/or consent.

Further analysis drew upon a view of techno-security (Weber, 2011; 2016) and its pervasive proliferation through the techno-securitisation of everyday life (Marin, 2017). This concept helped to draw attention to some of the complexity that people experience with surveillance systems on a day-to-day basis. Techno-securitisation includes the transfer of military ideas of tracking, identification and targeting of individuals - in other words, military desires for omniscience - into urban civil society (Graham, 2013). Hence techno-securitisation is becoming increasingly complex, multiple and encompassing, in turn provoking fear and anxiety.

Additionally, and as a result of its ubiquity, subsequent normalisation and covert nature, it often bypasses conscious recognition. This can result in the associated effects of everyday surveillance discourses and practices becoming difficult to process and hence to psychologically regulate. Therefore, citizens may adopt the following discursive position: there is no avoiding these systems and not much one can do about them, so it is probably better not to be consciously concerned about them. This discursive position leads to the practice of what is termed in this paper as surveillance-apatheia.

To develop this notion of surveillance-apathy, the analysis drew upon theorisations of 'affective atmospheres' (Anderson, 2009; Ellis, Tucker \& Harper, 2013), which follow a line of thought on affect that can be traced back to Spinoza through to Massumi (2002). These affect theories helped to contextualise the Stoic notion of apatheia (Knuuttila, 2004; Sorabji, 2000). Apatheia is the practice of maintaining a disposition through which the individual experiences minimal psychological disturbance. It appears to be one way of psychologically dealing with the techno-securitisation of everyday life which can give way to affects related to anxiety and fear. It is not that citizens are colluding or indifferent, but rather that deliberation would be psychologically demanding and can appear futile. It may therefore be better to manage the affects through habitual forms of suppression strategies: an attitude of surveillance-apatheia.

The attitude of apatheia discussed here is likely to be relevant for other areas of everyday life where digital technologies are pervasive. For example, there is an increasingly digital exposure to the horrific things that are occurring around the world; advertisers are creative in integrating brands into everyday web-content. It is difficult to how how palpable, effective and critical these practices are,, but they are likely to have some psychological impact, some being more poignant than others. It is likely that the related psycho-cultural processes are particularly significant for the effects of everyday techno-security as it is increasingly ubiquitous.

Perhaps this enquiry points to some of the difficulties of having insights into the affective activity related to techno-security, given its non-conscious nature. And of course, experiences are likely to be quite diverse; for example, people who belong to a particularly highly targeted group, or where workplace surveillance is much 
more targeted and intense, may have greater difficulty to develop an attitude of surveillance-apatheia. Further research is required to investigate these types of contexts.

\section{Reference List}

Anderson, B. (2009). Affective atmospheres. Emotion, space and society, 2(2), 77-81.

Beer, D. and Burrows, R. (2010). Consumption, presumption and participatory web cultures: An introduction. Journal of Consumer Culture, 10(1), 3-12.

Big Brother Watch (2016). Are They Still Watching? The cost of CCTV in an era of cuts. https://www.bigbrotherwatch.org.uk/wp-content/uploads/2016/02/Are-They-Still-Watching.pdf

Clarke, R. (1988). Information technology and dataveillance. Communication of the ACM, 31(5), 498-512.

Crawford, A., \& Hutchinson, S. (2015). Mapping the contours of 'Everyday Security': Time, space and emotion. The British Journal of Criminology, azv121v1-azv121

Cromby, J. (2011). Affecting qualitative health psychology. Health Psychology Review, 5(1), 79-96.

Cutting, A. (retrieved, 15//02/2016). http://www.huffingtonpost.co.uk/andrew-cutting/snooping-on-employeesemails b 8989968.html

The Daily Mail (2015). (retrieved 12/02/2016) http://www.dailymail.co.uk/news/article-3397433/Europeancourt-says-bosses-read-staff-s-private-messages.html

Deleuze, G., \& Guattari, F. (1987). A thousand plateaus: Capitalism and schizophrenia. Minneapolis: University of Minnesota Press.

Dencik, L. \& Cable, J. (2017). The advent of surveillance realism: Public opinion and activist responses to the Snowden leaks. International Journal of Communication, 11, 276-781.

Ellis, D., \& Tucker, I. (2015). Social Psychology of Emotion. London: Sage.

Ellis, D., Tucker, I., \& Harper, D. (2013). The affective atmospheres of surveillance. Theory and Psychology, 23(6), 840-855.

Ellis, D., Harper, D., and Tucker, I. (2013) 'The Dynamics of Impersonal Trust and Distrust in Surveillance Systems', Sociological Research Online, 18(3), p. 8.

European Court of Human Rights (2016). Press release: Monitoring of an employee's use of the Internet and his resulting dismissal was justified. ECHR 013 (2016), 12 January. Retrieved on 30 January from: http://hudoc.echr.coe.int/eng-press?i=003-5268557-6546344

Frerudi, F. (2007). Culture of fear revisited. Continuum: London.

Gregg, M., \& Seigworth, G. J. (2010). The affect theory reader. Durham, NC: Duke University Press.

The Guardian (2015a). (retrieved 12/02/2016) http://www.theguardian.com/commentisfree/2016/jan/15/theguardian-view-on-snooping-at-work-bosses-are-one-thing-but-dont-forget-big-brother

The Guardian (2015b) (Retrieved 21/04/2016) https://www.theguardian.com/technology/2015/feb/20/mobilephones-hacked-can-nsa-gchq-listen-to-our-phone-calls 
Hayes, B. (2012). The surveillance-industrial complex. In The Routledge Handbook of Surveillance Studies, edited by Kirstie Ball, Kevin Haggerty and David Lyon, 167-176. London: Routledge.

Internet World Stats (2013). United Kingdom: Internet usage Stats and market profile. (Retrieved 07/03/2016) https://www.internetworldstats.com/eu/uk.htm

Knuuttila, S. (2004). Emotions in Ancient and Medieval Philosophy. Oxford University Press.

Layton, R. (2000), Propatheia: Origen and Didymus on the Origin of the Passions. Vigiliae Christianae, 54(3), 262282.

Lyon, D. (2015). Surveillance after Snowden. Polity Press.

Massumi, B. (2002). Parables for the virtual: Movement, affect, sensation. Durham, NC: Duke University Press Books.

The Metro (retrieved 26/04/2016) http://metro.co.uk/2016/01/13/your-boss-now-has-the-right-to-snoop-onyour-private-online-messages-5619830/

Ofcom (2015). Facts and Figures. (retrieved 26/04/2016) http://media.ofcom.org.uk/facts/

Sampson, T., Maddison, S. \& Ellis. D. (2018). Affect and Social Media: Emotion, Mediation, Anxiety and Contagion. London, New York: Rowman \& Littlefield International

Solove, D. J. (2007). I've got nothing to hide and other misunderstandings of privacy. San Diego Law Review, 44, 745.

Sorabji, R. (2000). Emotion and Peace of Mind: From Stoic agitation to Christian temptation. Oxford University Press.

The Sun (retrieved 12/02/2016) http://www.thesun.co.uk/sol/homepage/features/6862448/All-the-ways-yourboss-can-spy-on-you.html

Vogel, K., (2015). Cruz partners with doner's 'psychographic' firm. Politico. Retrieved May 1, 2018.

Weber, J. (2011). Techno-security, risk and the militarization of every day life. The computational turn: Past, presents, futures? Proceeding of the First international conference of IACAP. 168-175.

Weber, J. (2016). Keep adding. On kill lists, drone warfare and the politics of databases. Environment and Planning D: Society and Space, 34(1) 107-125.

Webster, W. R., \& Murakami Wood, D. (2009). Living in surveillance societies: The normalisation of surveillance in Europe and the threat of Britain's bad example. Journal of Contemporary European Research, 5(2), 259-273.

Wetherell, M. (2012). Affect and emotion: A new social science understanding. London, UK: Sage.

Winner, L. (1977). Autonomous Technology: Technics Out-of-Control as a Theme in Political Thought. Cambridge, MA: MIT Press.

Wood, D. M. (Ed.), Ball, K., Lyon, D., Norris, C. \& Raab, C. (2006) A Report on the Surveillance Society. Wilmslow, UK: Office of the Information Commissioner/Surveillance Studies Network.Ball,

YOUGOV/TELEGRAPH. (2006) Survey Results.

http://www.yougov.co.uk/extranets/ygarchives/content/pdf/TEL060101024 3.pdf 


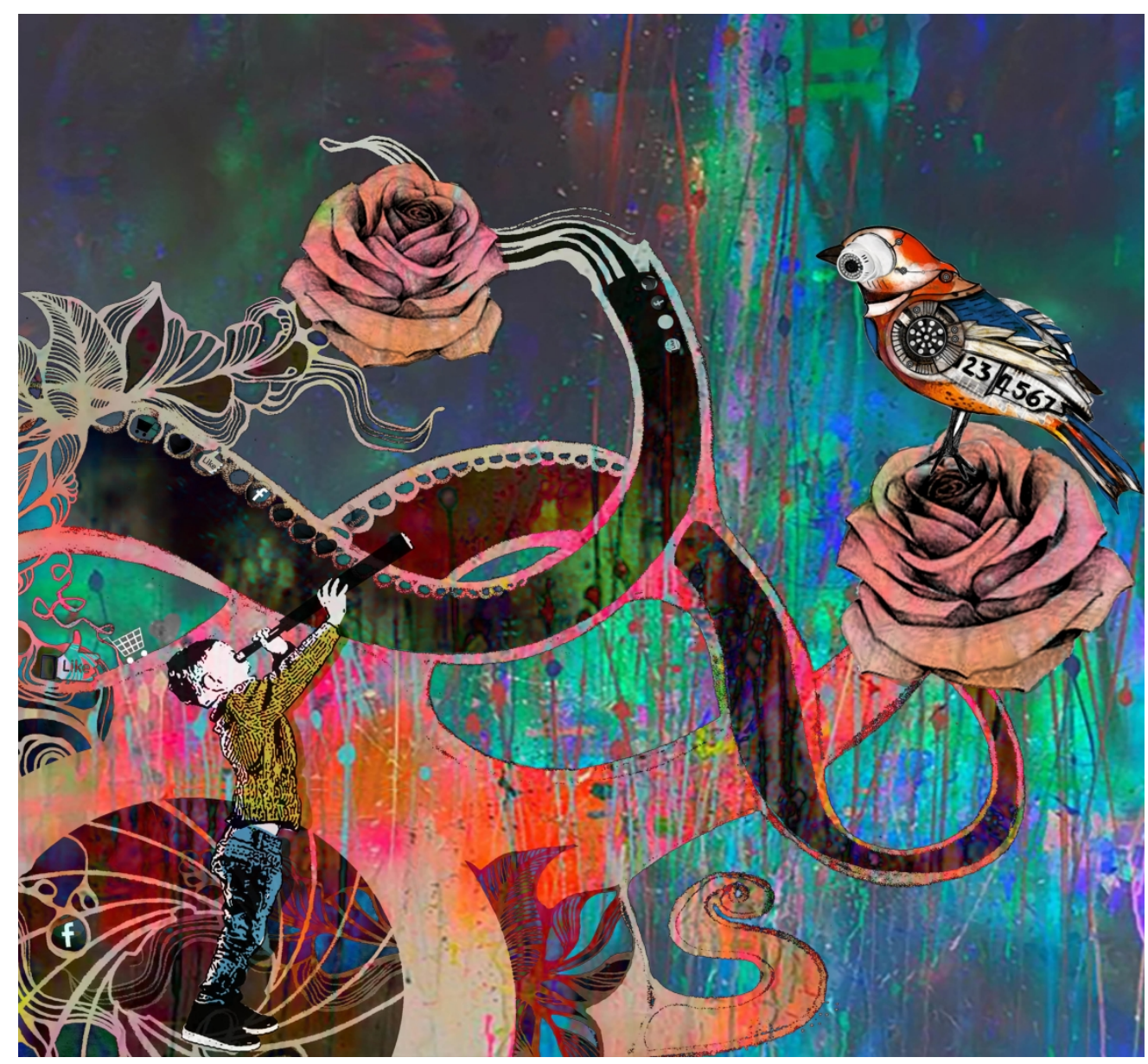

'Surveillance Apatheia'. Credit: Nicola Carter (nicola.carter@mail.com) $250 \times 231 \mathrm{~mm}(300 \times 300 \mathrm{DPI})$ 


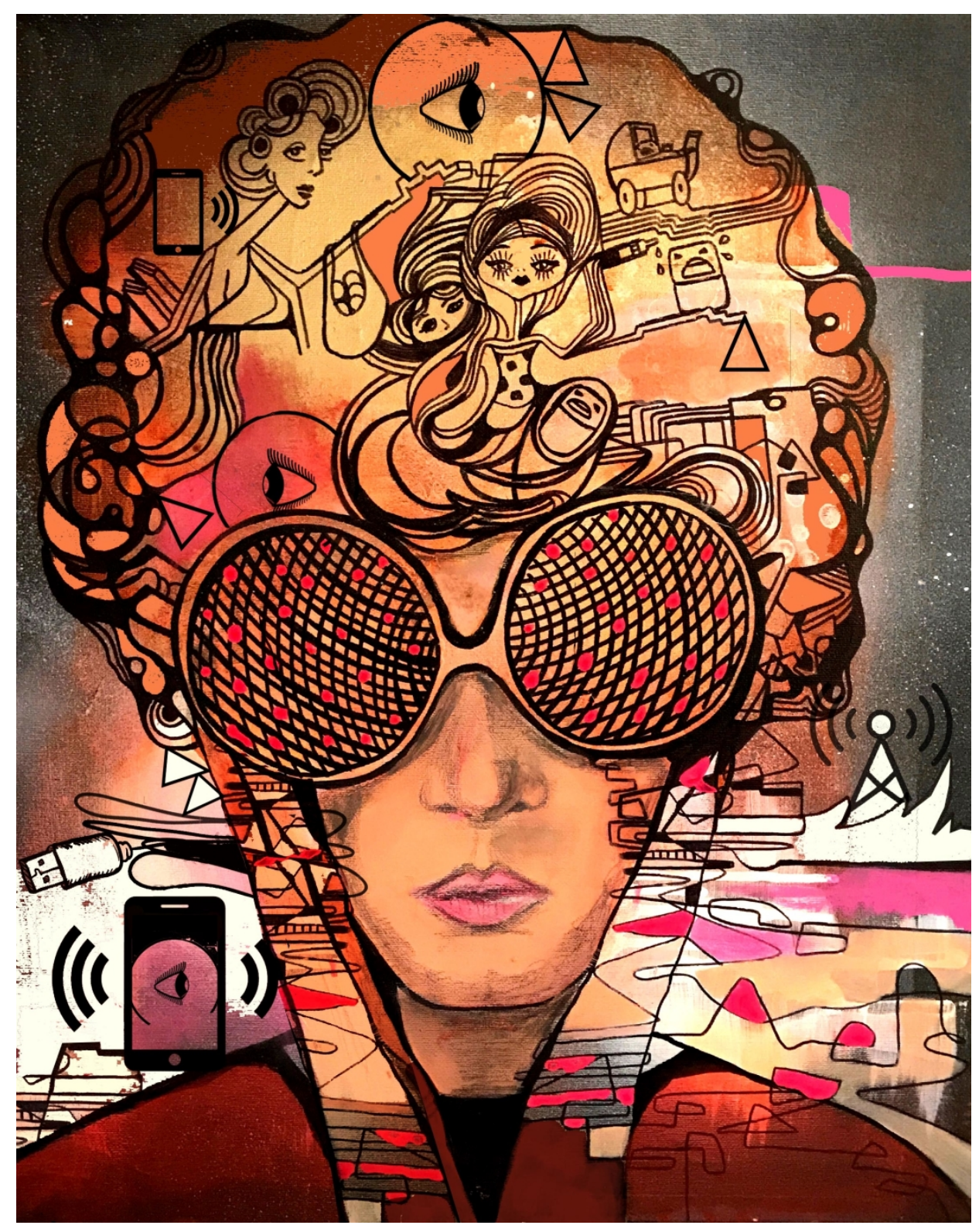

'Techno-vibes'. Credit: Nicola Carter (nicola.carter@mail.com) $194 \times 245 \mathrm{~mm}(300 \times 300 \mathrm{DPI})$ 